8. Двинских С.А., Клименко Д.Е., Ларченко О.В., Минкин К.А. Анализ русловых деформаций в нижнем бьефе Воткинского водохранилища // Четвертые Виноградовские чтения. Гидрология от познания к мировоззрению: сб. докл. Междунар. науч. конф. памяти выдающегося русского ученого Ю.Б. Виноградова / Санкт-Петербургский гос. ун-т. - СПб., 2020. - С. 600-605.

9. HEC-RAS River Analysis System: Hydraulic Reference Manual. Version 5.0 (CPD-69) / Gary W. Brunner. - February 2016. $-547 \mathrm{p}$.

10. RiverFlow2D Two-Dimensional River Dynamics Model: Reference Manual, August 2016. - URL: http://www.hydronia.com.

\title{
ОЦЕНКА ПОСТУПЛЕНИЯ МЫШЬЯКА В ГИДРОСФЕРУ КИЗЕЛОВСКОГО УГОЛЬНОГО БАССЕЙНА
}

\author{
Н.Ф. Фетисова \\ Горный институт УрО РАН, г. Пермь
}

\begin{abstract}
Аннотация: Работа посвящена количественной и качественной оценке поступления мышьяка с кислыми шахтными водами Кизеловского угольного бассейна в поверхностную гидросферу. Масса выносимого с шахтными водами мышьяка определена с учетом объема изливов и концентраций растворенного вещества. Гидрогеохимическое моделирование, выполненное с помощью программного кода PHREEQC, показало, что основными неорганическими формами мышьяка в шахтных водах являются арсенаты.
\end{abstract}

Ключевые слова: Кизеловский угольный бассейн, кислые шахтные воды, мышьяк, форма нахождения, оценка массы поступления.

Мышьяк (As) является естественным компонентом земной коры и встречается в природе повсеместно. По оценкам ученых кларк As в верхней части континентальной земной коры изменяется в диапазоне 1,5-5,7 мг/кг [2]. Его поступление в окружающую среду обусловлено как естественными процессами, так и антропогенной деятельностью. Значительный вклад в загрязнение окружающей среды мышьяком вносит горнодобывающая промышленность. Мышьяк, наряду с другими металлами, является типичным загрязнителем, присутствующим в кислых шахтных водах.

Известно, что в небольших количествах мышьяк необходим для жизни. Природные минеральные воды, содержащие мышьяк, используются в лечебнопрофилактических целях. Однако и очень малые дозы мышьяка могут оказывать пагубное воздействие, если их попадание в организм, например, с пищей или водой, происходит в течение длительного времени. Установлена связь между «хроническим» попаданием мышьяка в организм и раком кожи, печени, почек и мочевого пузыря. Выявлена связь между увеличением заболеваемости раком легких не только при вдыхании соединений мышьяка, но и при потреблении его с питьевой водой [9]. Предельно допустимая концентрация мышьяка (ПДК) в питьевых водах, утвержденная Всемирной организации здравоохранения (ВО3) и принятая в большинстве стран мира, составляет 0,01 мг/дм ${ }^{3}$ (Табл. 1). Безопасная концентрация As в водоемах рыбохозяйственного назначения не превышает 0,05 мг/дм ${ }^{3}$.

Мышьяк - это металлоид, относящийся к 15-й группе (по устаревшей классификации - к главной подгруппе пятой группы) периодической таблицы. Мышьяк ковалентно связывается с большинством металлов и неметаллов, а также 
образует стабильные органические соединения [9]. В природных системах мышьяк может существовать в четырех степенях окисления $(-3,0,+3$ и +5$)$. Самородный (элементарный) мышьяк встречается редко. Арсин $\left(\mathrm{AsH}_{3}\right)$ является очень ядовитым и легковоспламеняющимся газом. Следы токсичного арсина можно обнаружить в газах, исходящих из бескислородной среды [11]. В природных водах основными степенями окисления мышьяка являются +5 (арсенат $\mathrm{AsO}_{4}{ }^{3-}$ ) и +3 (метаарсенит $\mathrm{AsO}_{2}{ }^{-}$, ортоарсенит $\mathrm{AsO}_{3}{ }^{{ }^{-}}$) [5]. Двумя наиболее важными геохимическими факторами, определяющими состав растворенных форм мышьяка и его мобильность в окружающей среде, являются рН и окислительновосстано-вительные условия (Eh) [5]. В окислительных условиях $\left(p e^{1}+\mathrm{pH}>10\right)$ арсенат является преобладающим видом мышьяка, в то время как в умеренно восстановительных и восстановительных условиях $(p e+\mathrm{pH}<8)$ арсенит являются наиболее доминирующей формой [7]. Преобладающей формой неорганического_мышьяка в водных аэробных средах является арсенат (дигидроарсенат $\mathrm{H}_{2} \mathrm{AsO}_{4}{ }^{-}$и гидроарсенат $\mathrm{HAsO}_{4}{ }^{-}$), тогда как арсенит (ортомышьяковистая кислота $\mathrm{H}_{3} \mathrm{AsO}_{3}$ и дигидроортоарсенит $\mathrm{H}_{2} \mathrm{AsO}_{3}$ ) более распространен в бескислородных средах [11].

ПДК мышьяка в воде (мг/дм³), принятые в России и за рубежом

Таблица 1

\begin{tabular}{|c|c|c|c|c|}
\hline Россия & Россия & ВОЗ & ЕС & США \\
ПДК рх & ПДК хоз.-пит. & ПДК пит. & ПДК пит. & ПДК \\
Приказ № & СанПиН & Рекомендации... & Директива & Пит. \\
552 & $1.2 .3685-21$ & {$[13]$} & $98 / 83 / \mathrm{EC}[8]$ & US EPA \\
& 0,01 & 0,01 & 0,01 & 0,01 \\
\hline 0,05 & & & 0.01 \\
\hline
\end{tabular}

Действующие нормативы качества питьевой воды не делают различий между арсенитом и арсенатом, учитывая только общее содержание мышьяка в воде. Известно, что соединения трехвалентного мышьяка более мобильны и во много раз более токсичны, чем их пятивалентные аналоги, а неорганические соединения мышьяка более токсичны, чем органические [5, 9]. Элементарный мышьяк - одна из наименее токсичных форм [9]. Арсенат сильно адсорбируется на поверхности некоторых распространенных минералов, таких как ферригидрит и оксид алюминия (глинозем), что ограничивает его гидрологическую подв ижность. Арсенит адсорбируется на меньшем количестве минералов, что делает его более подвижным оксианионом [11].

Таким образом, при изучении характера загрязнения мышьяком и процессов переноса важно принимать во внимание форму нахождения химического элемента, которая зависит от окружающих геохимических условий. Целью данной работы является оценка количества мышьяка, поступающего с кислыми шахтными водами Кизеловского угольного бассейна в поверхностную гидросферу, а также определение основных неорганических форм нахождения мышьяка в шахтных водах с помощью гидрогеохимического моделирования.

${ }^{1} p e-$ отрицательный логарифм активности электронов: $p e=-\log \left(\mathrm{e}^{-}\right), p e=16.9 \mathrm{Eh}$. 
В кислых шахтных водах Кизеловского угольного бассейна по данным, полученным в ходе гидрохимического мониторинга [1], мышьяк присутствует в концентрациях от 0,005 до $0,128 \mathrm{мг} /$ дм $^{3}$ и в среднем составляет примерно 0,028 мг/дм ${ }^{3}$ (табл. 2). В большинстве изливов содержание мышьяка в несколько раз превышает ПДК. Расположение шахт и мест разгрузки кислых шахтных вод на поверхность показано в работе [3]. Масса мышьяка, поступающего в речную сеть района исследования (кг/год), была определена с учетом его концентраций в шахтных водах и расходами изливов, полученными в ходе режимных наблюдений [1]. Результаты расчета по данным трехлетних наблюдений (2015-2017 гг.) представлены в табл. 2. Наиболее высокие концентрации мышьяка наблюдаются в изливах шахт «Им. Крупской» и «Им. Володарского», где его содержание достигает 0,082 и $0,128 \mathrm{мг} /$ дм $^{3}$, соответственно. Однако наибольший вклад в загрязнение поверхностных вод мышьяком, в среднем 115-127 кг/год, вносят изливы шахт «Им. Ленина», «Им. Калинина» и «Таежная», что обусловлено большими расходами изливов при меньшем содержании As. В целом среднегодовое поступление мышьяка с шахтными водами Кизеловского бассейна в речную сеть территории Пермского Предуралья составляет около 554,7 кг/год.

Гидрогеохимическое моделирование с использованием программного кода PHREEQC (с базой данных WATEQ4f) было выполнено для вод шахты «Таежная». Усредненный химический состав воды приведен в работе [4]. Водородный показатель $(\mathrm{pH})$ рассмотренных вод изменяется от 3,0 до 3,4 и в среднем составляет 3,3. Показатель окислительно-восстановительных условий (pe), рассчитанный для шахтных вод по коэффициентам активностей ионных пар $\mathrm{NH}_{4}{ }^{+} / \mathrm{NO}_{3}{ }^{-}$, изменяется в пределах от 11,6 до 12,1 , со средним значением 11,8 .

Результаты гидрохимического моделирования подтвердили, что основными неорганическими формами мышьяка в шахтных водах являются арсенаты. В распределении неорганических форм $\mathrm{As}^{+5}$ в данных окислительновосстановительных условиях, как и предполагалось, доминирует $\mathrm{H}_{2} \mathrm{AsO}_{4}$ $(92,60 \%)$. На мышьяковую кислоту $\mathrm{H}_{3} \mathrm{AsO}_{4}$ приходится около 7,38\% от содержащегося в воде мышьяка. Незначительная часть мышьяка (около 0,02\%) может присутствовать в виде $\mathrm{HAsO}_{4}{ }^{2}$.

Таким образом, мышьяк в шахтных водах находится в окисленном состоянии $\mathrm{As}^{+5}$, соединения которого, как известно, менее растворимы и менее токсичны для живых организмов. $\mathrm{As}^{+5}$ легче удаляется из растворенной фазы с помощью механизмов адсорбции и/или соосаждения, чем $\mathrm{As}^{+3}[6,14]$.

Поступление мышьяка в поверхностную гидросферу Пермского Предуралья не ограничено изливами шахтных вод. Стоки с породных отвалов и разгрузка загрязненных подземных вод в виде родников также являются источниками поступления мышьяка в водные объекты. В природных водах мышьяк может вступать в окислительно-восстановительные реакции, в том числе с органическими соединениями, осаждаться и адсорбироваться на минералах, преимущественно на оксидах и гидроксидах железа и алюминия $[6,9,11]$. Часть адсорбированного мышьяка может замещаться распространенными анионами (например, фосфатами и сульфидами), что приводит к их повторной мобилизации [7]. Во влажной почве может происходить восстановление арсената до арсенита [12]. Трансформации соединений мышьяка в природных водах территории исследования, включение As в состав труднорастворимых соединений и возможность повторного загрязнения требуют дальнейшего глубокого изучения. 


\begin{tabular}{|c|c|c|c|c|c|c|c|c|c|c|c|c|c|c|c|c|c|c|c|}
\hline 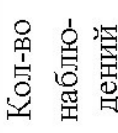 & $a$ & $a$ & $a 1$ & $a$ & $a$ & a* & $*$ & $a$ & $\infty$ & $a$ & $a$ & $\infty$ & $a / \alpha$ & $\infty \frac{*}{*}$ & a & $\stackrel{\infty}{\check{r}}$ & 甫 & $\stackrel{\infty}{+}$ & 字 \\
\hline 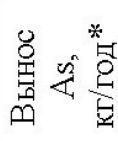 & $\begin{array}{l}\hat{⿵} \\
n^{n}\end{array}$ & 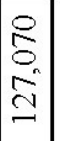 & $\begin{array}{c}\dot{2} \\
\dot{\delta} \\
\hat{i}\end{array}$ & 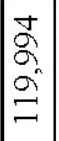 & 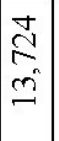 & $\mid \begin{array}{c}2 \\
m \\
m \\
m\end{array}$ & 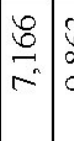 & $\begin{array}{l}n \\
0 \\
\infty \\
0 \\
0\end{array}$ & 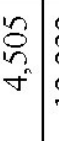 & 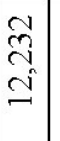 & $\begin{array}{l}\stackrel{8}{\infty} \\
\stackrel{0}{ \pm} \\
=\end{array}$ & $\begin{array}{l}\tilde{2} \\
2 \\
= \\
= \\
=\end{array}$ & 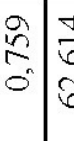 & 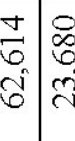 & 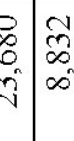 & 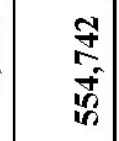 & $\begin{array}{l}\overrightarrow{7} \\
⿱ \\
\vec{D} \\
i n\end{array}$ & 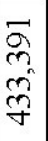 & $\begin{array}{l}0 \\
g \\
g \\
g \\
0\end{array}$ \\
\hline 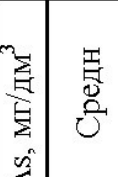 & $\begin{array}{l}0 \\
\delta \\
0\end{array}$ & $\begin{array}{l}2 \\
8 \\
0\end{array}$ & $\begin{array}{l}\infty \\
\stackrel{\infty}{\delta} \\
0\end{array}$ & $\begin{array}{l} \\
8 \\
0 \\
0\end{array}$ & $\begin{array}{l}8 \\
8 \\
0 \\
0\end{array}$ & \begin{tabular}{|l|} 
\\
\\
0 \\
0
\end{tabular} & 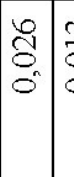 & $\begin{array}{l}m \\
\stackrel{n}{0} \\
0\end{array}$ & $\begin{array}{l}0 \\
0 \\
0 \\
0\end{array}$ & $\begin{array}{l}\vec{\infty} \\
\dot{8} \\
0\end{array}$ & 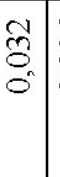 & \begin{tabular}{l|l}
0 & 0 \\
0 & \\
0 & \\
0
\end{tabular} & \begin{tabular}{l|l}
8 & $\overline{8}$ \\
8 & $\overline{9}$
\end{tabular} & \begin{tabular}{l|l}
$\vec{E}$ & 0 \\
& 0 \\
0 & 0 \\
0
\end{tabular} & 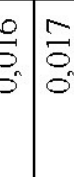 & 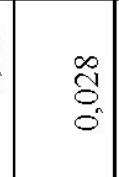 & $\begin{array}{l}8 \\
8 \\
0 \\
0\end{array}$ & 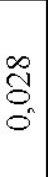 & 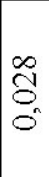 \\
\hline 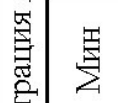 & $\tilde{8}_{0}^{\circ}$ & $\begin{array}{l}8 \\
8 \\
0 \\
0\end{array}$ & $\begin{array}{c}m \\
\stackrel{n}{0} \\
0\end{array}$ & $\mid \begin{array}{l}0 \\
8 \\
0\end{array}$ & $\mid \begin{array}{l}0 \\
0 \\
0 \\
0\end{array}$ & $\left|\begin{array}{l}0 \\
8 \\
0 \\
0\end{array}\right|$ & 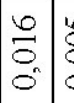 & $\begin{array}{l}8 \\
\delta \\
0\end{array}$ & $\begin{array}{l}\infty \\
8 \\
0 \\
0\end{array}$ & $\begin{array}{l}\infty \\
0_{n} \\
0\end{array}$ & $\begin{array}{l}\delta \\
\delta^{\prime}\end{array}$ & $\vec{\sigma}_{0}$ & 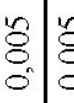 & 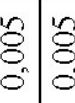 & 8 & 8 & 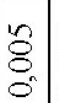 & $\begin{array}{l}n \\
8 \\
0 \\
0\end{array}$ & 8 \\
\hline 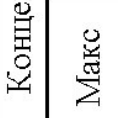 & $\begin{array}{l}\infty \\
8 \\
8 \\
0\end{array}$ & $\begin{array}{l}0 \\
8 \\
8 \\
0\end{array}$ & $\begin{array}{l}\vec{J} \\
\dot{O}^{\prime}\end{array}$ & 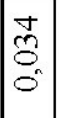 & $\begin{array}{l}\tilde{1} \\
\mathscr{8} \\
0 \\
0\end{array}$ & $\begin{array}{l}0 \\
0 \\
0 \\
0\end{array}$ & \begin{tabular}{l|l} 
\\
\end{tabular} & $\vec{~}$ & 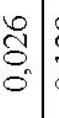 & $\begin{array}{l}\infty \\
\stackrel{1}{J} \\
0\end{array}$ & $\begin{array}{l}0 \\
0 \\
0 \\
0\end{array}$ & \begin{tabular}{l|l}
$\mathscr{2}$ & $\bar{\delta}$ \\
$\hat{\delta}$ & $\bar{\delta}$
\end{tabular} & 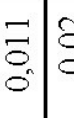 & \begin{tabular}{c|c}
8 & 8 \\
0 & 8 \\
0 & 0 \\
0
\end{tabular} & $\begin{array}{l}8 \\
\end{array}$ & $\begin{array}{c}\infty \\
\stackrel{0}{0} \\
0\end{array}$ & $\begin{array}{l}\stackrel{8}{\mathrm{~J}} \\
\overrightarrow{0}\end{array}$ & $\begin{array}{l}8 \\
8 \\
8 \\
0\end{array}$ & $\begin{array}{l}\infty \\
\text { J } \\
0\end{array}$ \\
\hline 崖 & $\stackrel{5}{\Xi}$ & $\begin{array}{l}\infty \\
\stackrel{\infty}{\sigma} \\
\vec{\nabla}\end{array}$ & $\begin{array}{l}J^{7} \\
2\end{array}$ & $\begin{array}{l}\exists \\
= \\
\dot{\infty} \\
0\end{array}$ & $\begin{array}{l}8 \\
\therefore \\
n\end{array}$ & $\begin{array}{l}m \\
\hat{m} \\
0\end{array}$ & $\mid \begin{array}{l}\bar{b} \\
\bar{m}\end{array}$ & 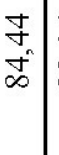 & $\begin{array}{c} \pm \\
\vec{n} \\
m\end{array}$ & $\stackrel{m}{\stackrel{m}{=}}$ & $\begin{array}{l}2 \\
\infty \\
0^{n} \\
\vec{\nabla}\end{array}$ & 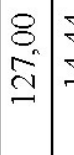 & 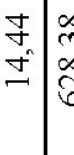 & \begin{tabular}{c|c}
$\infty$ & 0 \\
$m$ & $n$ \\
0 & $n$ \\
0 & $n$
\end{tabular} & \begin{tabular}{l|l}
8 & $R$ \\
6 & 0 \\
0 & $n$
\end{tabular} & 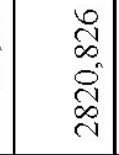 & 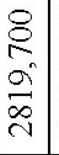 & 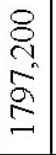 & 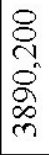 \\
\hline 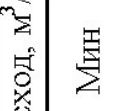 & $\stackrel{\circ}{r}$ & 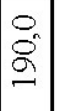 & $\begin{array}{l}\circ \\
\stackrel{n}{n}\end{array}$ & $\begin{array}{l}0 \\
\mathscr{b} \\
\stackrel{y}{1}\end{array}$ & $\stackrel{0}{\circ}$ & $\begin{array}{c}0 \\
\hat{i}\end{array}$ & $\stackrel{\circ}{-}$ & $\stackrel{\circ}{=}$ & $\begin{array}{l}0 \\
\vec{N} \\
\vec{N}\end{array}$ & $\stackrel{\circ}{-}$ & $\begin{array}{l}0 \\
\text { f } \\
\text { ป }\end{array}$ & $0^{\circ}$ & $\stackrel{\circ}{+} \mid \frac{G}{\sigma}$ & 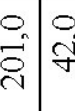 & \begin{tabular}{c|c}
0 & 0 \\
$y$ & \multirow{N}{*}{}
\end{tabular} & $\begin{array}{l}0 \\
\hat{n} \\
\stackrel{\Xi}{ }\end{array}$ & $\begin{array}{l}0 \\
\infty \\
\infty \\
\\
\end{array}$ & 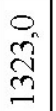 & $\begin{array}{l}0 \\
\overbrace{\hat{~}} \\
\text { ते }\end{array}$ \\
\hline 惢 & $\begin{array}{l}0 \\
\vartheta^{n}\end{array}$ & $\begin{array}{c}0 \\
\hat{N} \\
\infty \\
\infty\end{array} \mid$ & $\begin{array}{l}\stackrel{0}{\delta} \\
\stackrel{\delta}{\delta}\end{array}$ & 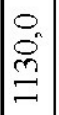 & $\begin{array}{l}8 \\
8\end{array}$ & $\mid \begin{array}{c}0 \\
n \\
2\end{array}$ & \begin{tabular}{l|l}
$\circ$ & 5 \\
\hdashline & \\
\hdashline
\end{tabular} & $\begin{array}{l}0 \\
\stackrel{8}{8} \\
\stackrel{2}{1}\end{array}$ & \begin{tabular}{l|l}
0 \\
$\tilde{f}^{0}$
\end{tabular} & $\begin{array}{l}0 \\
\infty \\
\infty\end{array}$ & \begin{tabular}{l}
0 \\
\multirow{J}{0}{} \\
$\delta$
\end{tabular} & 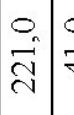 & \begin{tabular}{l|l}
0 & $g$ \\
$\vec{f}$ & $g$ \\
\end{tabular} & \begin{tabular}{l|l}
0 & 0 \\
0 & \\
$\infty$ & 0 \\
$=$ & $m$
\end{tabular} & 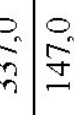 & $\begin{array}{l}\stackrel{0}{8} \\
8 \\
i \\
i n\end{array}$ & $\begin{array}{l}0 \\
\infty \\
\infty \\
\infty \\
m\end{array}$ & 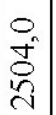 & $\begin{array}{l}0 \\
m \\
m \\
n \\
n\end{array}$ \\
\hline 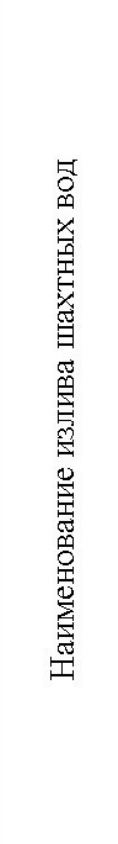 & 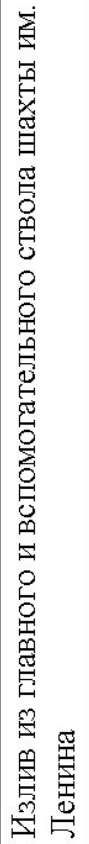 & 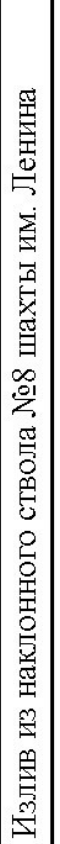 & 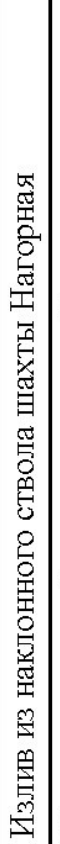 & 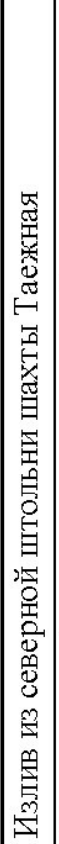 & 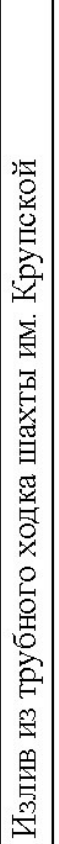 & 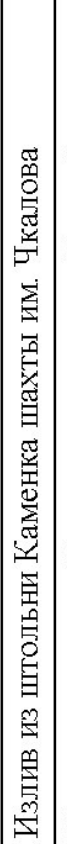 & 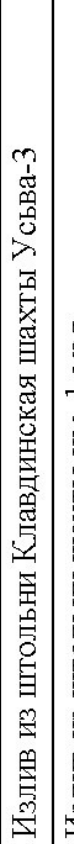 & 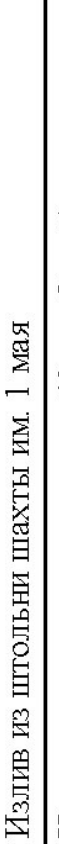 & 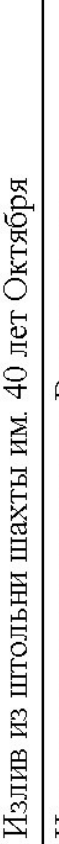 & 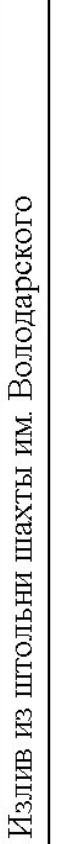 & 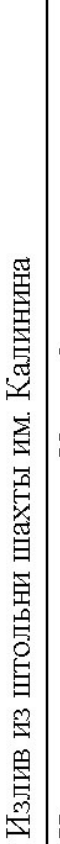 & 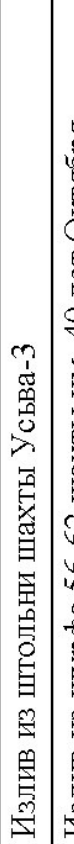 & 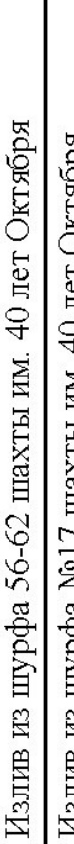 & 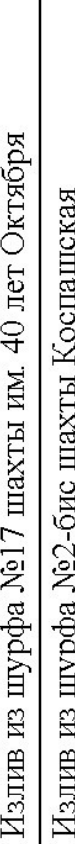 & 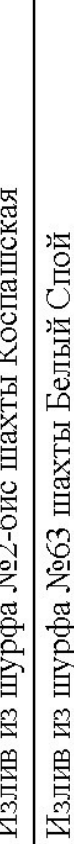 & 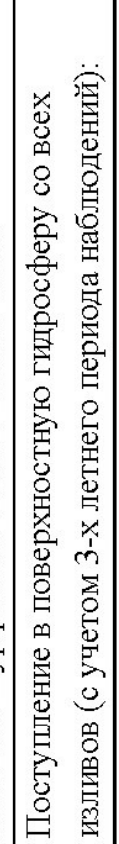 & $\begin{array}{l}n \\
\stackrel{n}{\circ} \\
\underset{ల}{్ ల n}\end{array}$ & 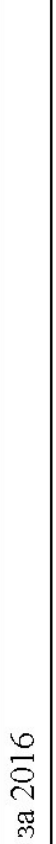 & 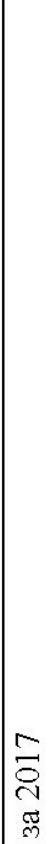 \\
\hline 说肯 & & $\sim$ & $m$ & $\nabla$ & in & 6 & 10 & $\infty$ & $a$ & $\stackrel{9}{9}$ & $=$ & $\cong$ & $m=$ & $\pm \because$ & $\therefore 10$ & & & & \\
\hline
\end{tabular}

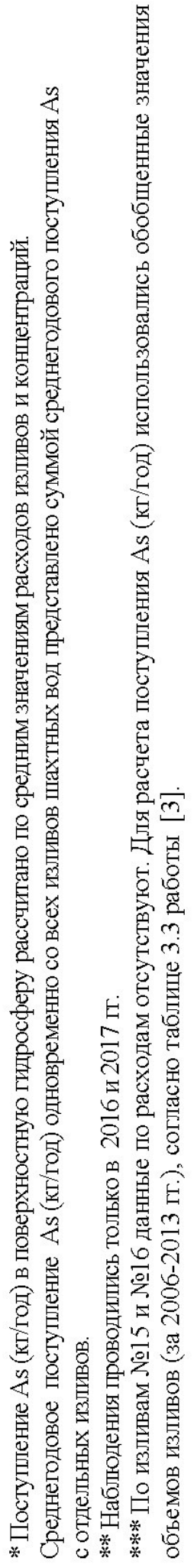

Исследования выполнены в рамках госзадания по теме № 0422-2018-007 «Обоснование мероприятий по контролю и управлению гидросферой в районах интенсивного недропользования» 


\section{БИБЛИОГРАФИЧЕСКИЙ СПИСОК}

1. Выполнение научно-исследовательской работы по минимизации и ликвидации воздействия кислых шахтных вод Кизеловского угольного бассейна на водные объекты Пермского края: отчет о НИР (итоговый) / Естественнонаучный институт ПГНИУ; рук. Максимович Н.Г. - Пермь, 2019. -

2. Касимов Н.С., Власов Д.В. Кларки химических элементов как эталоны сравнения в экогеохимии // Вестн. Моск. ун-та. Сер. 5. География. - 2015. - №2. - С. 7-17.

3. Максимович Н.Г., Пьянков С.В. Кизеловский угольный бассейн: экологические проблемы и пути решения / ПГНИУ. - Пермь, 2018. - 287 с.: ил..

4. Фетисова Н.Ф. Исследование форм миграции металлов в реках, подверженных влиянию шахтных вод Кизеловского угольного // Известия Томского политехнического ун-та. Инжиниринг георесурсов. - 2021. - Т. 332, № 1. - C. 141-152. - DOI: https://doi.org/10.18799/24131830/2021/1/3007.

5. Arsenic Geochemistry and Kd Values // Understanding Variation in Partition Coefficient, Kd Values. Vol. III. Review of Geochemistry and Available Kd Values for Americium, Arsenic, Curium, Iodine, Neptunium, Radium, and Technetium: EPA 402-R-04-002C. - Washington: DC, 2004. - P. 5.14-5.23. - URL: https://www.epa.gov/sites/production/files/2015-05/documents/402-r-04-002c.pdf.

6. Bhattacharya P., Frisbie S.H., Smith E., Naidu R., Jacks G., Sarkar B. Arsenic in the environment: a global perspective // Heavy metals in the environment, 1st Edn. / Red Sarkar B. - New York: Marcell Dekker Inc., 2002. - P. 147-215.

7. Cheng H., Hu Y., Luo J., Xu B., Zhao J. Geochemical processes controlling fate and transport of arsenic in acid mine drainage (AMD) and natural systems // Journal of Hazardous Materials. - 2009. - V. 165, № 1-3. P. 13-26. - DOI: https://doi.org/10.1016/j.jhazmat.2008.10.070.

8. Council Directive 98/83/EC of 3 November 1998 on the quality of water intended for human consumption. URL: https://eur-lex.europa.eu/legal-content/EN/TXT/?uri=CELEX:31998L0083 (дата обращения 09.04.21).

9. Hindmarsh J.T., Abernethy C.O., Peters, G.R., and McCurdy, R.F. Environmental aspects of arsenic toxicity // Heavy Metals in the Environment / ed. Sarkar B., Marcell Dekker Inc. - 1st Edn., - New York, 2002. - P. 217229.

10. National Primary Drinking Water Regulations. US EPA. - URL: https://www.epa.gov/ground-water-anddrinking-water/national-primary-drinking-water-regulations (дата обращения 09.04.21).

11. Oremland R.S., Stolz J.F. The ecology of arsenic // Science. - 2003. - V. 300, № 5621. - P. 939-944. DOI: $10.1126 /$ science. 1081903.

12. Rochette E.A., Li G.C., Fendorf S.E. Stability of arsenate minerals in soil under biotically generated reducing conditions // Soil Science Society of America Journal. - 1998. - Vol. 62, № 6. - P. 1530-1537. - DOI: https://doi.org/10.2136/sssaj1998.03615995006200060008x.

13. WHO Guidelines for drinking-water quality, fourth edition. - 2011. - URL: https://www.who.int/water_sanitation_health/publications/2011/dwq_guidelines/en/ (дата обращения 09.04.21).

14. Wilkie, J.A., Hering, J.G.: Adsorption of arsenic onto hydrous ferric oxide: Effects of adsorbate/adsorbent ratios and co-occuring solutes // Colloids and Surfaces A: Physicochemical and Engineering Aspects. 1996. - V. 107. - P. 97-110. - DOI: https://doi.org/10.1016/0927-7757(95)03368-8. 